\title{
Coeliac disease occurs in Asian children living in Wales
}

\author{
K. Payne ${ }^{1}$, D. P. Tuthill ${ }^{2}$, I. H. Davies ${ }^{2}$ and H. R. Jenkins ${ }^{2}$ \\ Cardiff University ${ }^{1}$ and Children's Hospital for Wales ${ }^{2}$, Heath Park, Cardiff CF14 4XW, UK
}

Coeliac disease is often thought of as a disease of Mediterranean and Irish ${ }^{(1)}$ aetiology and not occurring in the Asian community. However, previous studies have highlighted areas in northern India where coeliac disease is prevalent ${ }^{(2)}$. In the UK coeliac disease affects approximately $1 \%$ of the population and is frequently under-diagnosed throughout all population groups. The aim of the present study was to determine the detection of coeliac disease amongst the Asian childhood population residing in mid and southeast Wales. All cases of children diagnosed as having coeliac disease between 1990 and 2006 were assessed. Cases from the whole of mid and southeast Wales were identified from histological and serological records and clinic letters. All cases were endoscopically diagnosed at the Children's Hospital for Wales. The Registrar General's census data were used to estimate the childhood population.

A total of ninety-nine children were diagnosed as having coeliac disease (ninety-four Caucasian; five Asian). According to 2001 census data 358846 children aged < 17 years were resident within mid and southeast Wales (342 579 Caucasian children; 6664 Asian children).

\begin{tabular}{lc}
\hline & $\begin{array}{c}\text { Prevalence of diagnosed } \\
\text { coeliac disease }(\%)\end{array}$ \\
\hline All children & 0.03 \\
Caucasian children & 0.03 \\
Asian children & 0.08 \\
\hline
\end{tabular}

Analysis $\left(\chi^{2}\right)$ with Yates correction shows a borderline significant increased frequency of coeliac disease in the Asian population $(P=0.055)$.

Most cases of coeliac disease still remain undiagnosed. The authors wish to draw attention to the existence of coeliac disease in the UK Asian population.

1. McMillan SA, Watson RP, McCrum EE et al. (1996) Gut 39, 43-47.

2. Sood A, Midha V, Sood N et al. (2006) J Gastroenterol Hepatol 21, 1622-1625. 